Research article

\title{
Management of turbidity current venting in reservoirs under different bed slopes
}

\author{
Sabine Chamoun*, Giovanni De Cesare, Anton J. Schleiss \\ Laboratory of Hydraulic Constructions (LCH), Ecole Polytechnique Fédérale de Lausanne (EPFL), Station 18, CH-1015 Lausanne, Switzerland
}

\section{A R T I C L E I N F O}

\section{Article history:}

Received 16 February 2017

Received in revised form

7 September 2017

Accepted 9 September 2017

\section{Keywords:}

Reservoir sedimentation management

Turbidity currents

Downstream environment

Reservoir bed slope

Outflow discharge

Venting efficiency

\begin{abstract}
A B S T R A C T
The lifetime and efficiency of dams is endangered by the process of sedimentation. To ensure the sustainable use of reservoirs, many sediment management techniques exist, among which venting of turbidity currents. Nevertheless, a number of practical questions remain unanswered due to a lack of systematic investigations. The present research introduces venting and evaluates its performance using an experimental model. In the latter, turbidity currents travel on a smooth bed towards the dam and venting is applied through a rectangular bottom outlet. The combined effect of outflow discharge and bed slopes on the sediment release efficiency of venting is studied based on different criteria. Several outflow discharges are tested using three different bed slopes (i.e., $0 \%, 2.4 \%$ and $5.0 \%$ ). Steeper slopes yield higher venting efficiency. Additionally, the optimal outflow discharge leading to the largest venting efficiency with the lowest water loss increases when moving from the horizontal bed to the inclined positions.
\end{abstract}

๑) 2017 Elsevier Ltd. All rights reserved.

\section{Introduction}

Reservoir operations must fulfill several requirements. On one hand, the long-term use of reservoirs should be ensured while meeting its purposes such as electricity generation, water supply for irrigation and households, flood protection, flow regulation and navigation. On the other hand, reservoirs cause the obstruction of rivers and should be operated in a way to minimize the environmental impacts downstream. Sedimentation of reservoirs is a process that affects the sustainability of reservoirs by reducing their storage capacity and simultaneously leads to downstream sediment impoverishment. For these reasons, managing reservoir sedimentation is of great importance. Many techniques to mitigate reservoir sediments are applied in reservoirs around the world (Annandale, 2005; Kantoush and Sumi, 2010; Schleiss, 2013; Schleiss et al., 2016). Different criteria exist for choosing the most efficient sediment management strategy for a specific reservoir (Palmieri et al., 2001). For instance, flushing of the reservoir can be performed if enough storage is available as large amounts of water are flushed downstream in a relatively short period of time (Lai and Shen, 1996). Also, high suspended sediment concentrations (Espa

\footnotetext{
* Corresponding author.

E-mail address: sabine.chamoun@epfl.ch (S. Chamoun).
}

et al., 2016) and ecological problems (Chung et al., 2008) might occur in the downstream river during flushing.

Nevertheless, fine and coarse sediments are mostly transported from the watershed into reservoirs during flood events. The coarse sediments settle at the entrance of the reservoirs forming a delta and the fine sediments can be transported along the reservoir down to the dam, mainly due to the formation of turbidity currents (Fan and Morris, 1992). The latter are sediment-laden density currents formed during flood events (Meiburg and Kneller, 2010). Once turbidity currents enter the reservoir, they plunge below the clear water surface due to their higher density. If the density difference between the clear water and the turbidity current is sufficiently high, the current can travel long distances (e.g., $80 \mathrm{~km}$ in Sanmenxia reservoir (Fan, 1986) and $129 \mathrm{~km}$ in Lake Mead (Morris and Fan, 1997)) until reaching the dam where a muddy lake is formed. If no low-level outlet or intake is opened to evacuate the sediments at the right time, the suspended sediments in the muddy lake settle and may consolidate. Apart from filling up the reservoir, sediment deposits can block water release structures and lead to the abrasion of hydro-mechanical equipment. Many researchers have studied the dynamics of turbidity currents. For instance, Lee and Yu (1997) have experimentally studied turbidity currents in reservoirs, particularly the plunge point characteristics as well as velocity and concentration profiles. Lamb et al. (2004) described the deposits induced by surging and continuous turbidity currents in intraslope 
minibasins, inspired by the minibasins found in the Gulf of Mexico while Lowe (1982) presented depositional models of different types of turbidity currents based on their grain population. Other researchers also highlighted different aspects of turbidity currents (Alavian et al., 1992; Garcia and Parker, 1993; Kneller and Buckee, 2000; Simpson and Britter, 1979).

In the particular case of sedimentation due to turbidity currents, venting through bottom outlets or intakes is highly recommended (Chamoun et al., 2016a). This technique has both economic and environmental advantages because outflow discharges used during venting and the resulting sediment concentrations are relatively low. By directly transiting the suspended sediments contained in turbidity currents, the eco-morphological continuity in terms of fine sediments is preserved.

Venting of turbidity currents is documented in numerous reservoirs worldwide (Chamoun et al., 2016a). Lee et al. (2014) investigated venting operations in the Tsengwen reservoir in Taiwan through a hybrid numerical, theoretical and experimental approach leading to a formula used to predict sediment concentrations and venting efficiencies. Fan (1986) proposed a methodology to estimate the characteristics of turbidity currents progressing in a reservoir and verified the method by applying venting in his model and successfully comparing the efficiency of venting with efficiency data observed in Guanting and Lake Mead reservoirs. Morris and Fan (1997) studied the influence of the reservoir's length and outflow discharge on the efficiency of venting operations based on data from Sanmenxia, Guanting, Heisongling and Lake Mead reservoirs. In Switzerland, at Mapragg reservoir, venting was economically optimized by implementing alarm systems that are triggered only when a turbidity current is reaching the dam with a minimum concentration of $2 \mathrm{~g} / \mathrm{l}$. In these cases, venting is considered to be a more profitable technique to mitigate the sediments than a future dredging (Müller and De Cesare, 2009). Many other field experiences provide crucial information on the operation of venting and its efficiency. Examples include the Dez Dam in Iran (Schleiss et al., 2010), the Iril Emda reservoir in Algeria (Raud, 1958), the Elephant Butte reservoir in the USA (Lara, 1960), and the Großsölk reservoir in Austria (Schneider et al., 2007) among others. However, systematic research on venting turbidity currents is still lacking and very few experimental studies (Chamoun et al., 2017; Fan, 1986; Lee et al., 2014; Yu et al., 2004) were carried out and published. Dam operators still miss the required knowledge needed for an optimal performance of venting operations. The main parameters affecting the efficiency of venting operations are well known from field experiences. Such parameters include the outlet discharge, the timing of venting (Chen and Zhao, 1992), the reservoir bed slope, and the position and size of the lowlevel outlet among others (Morris and Fan, 1997).

The present paper aims to experimentally investigate the operation of venting turbidity currents. The combined effect of bed slope and outflow discharge on the release efficiency of venting is studied. Due to the high measurement frequency, the effect of the duration of venting was also assessed. The experimental set-up, measuring instruments, testing procedure and analysis concept are firstly presented. The turbidity currents generated are then characterized, followed by the evaluation and discussion of the venting efficiency obtained under different bed slopes and outflow discharges. Finally, conclusions and an outlook are presented.

\section{Experimental set-up}

The tests are performed in a narrow flume of $8.55 \mathrm{~m}$ length, $0.27 \mathrm{~m}$ width, and $0.9 \mathrm{~m}$ height. The flume is divided into three parts i.e., a head tank, a main flume simulating the reservoir, and a downstream compartment (Fig. 2). It can be tilted from a horizontal position to a $5 \%$ slope. The water-sediment mixture is prepared in a mixing tank. The latter is equipped with a submerged pump that internally recirculates the mixture, ensuring good mixing by avoiding the settling of the sediments before and during the tests. The mixing tank is connected to the head tank by two pipes; a pumping pipe is used to pump the mixture from the mixing tank to the head tank and a restitution pipe used to spill the mixture back into the mixing tank. A rectangular inlet (Fig. 3(b)) is placed on the whole width of the flume, between the head tank and the main flume. A sliding gate (red slab in Fig. 1) serves to open and close the inlet. The sliding gate is kept closed (lower position) before the beginning of the test and is opened (higher position) to trigger the turbidity current and start the test. The main flume simulates the reservoir receiving the turbidity current. At a distance of $6.7 \mathrm{~m}$ from the inlet, a wall is positioned representing the dam with a bottom outlet $\left(12 \times 9 \mathrm{~cm}^{2}\right)$ centered on the width of the flume (Fig. 2(b)). The wall also serves as a weir spilling the clear water from the main flume during the turbidity current flow in order to maintain the clear water level. When venting begins, a venting pipe evacuates the flow into a downstream tank where concentration measurements are taken. Furthermore, a recirculation pipe is placed between the downstream compartment and the main flume. It serves for pumping clear water from the downstream compartment back into the main flume (through a diffusor shown in Fig. 3) in the cases where the outflow discharge is higher than the turbidity current's discharge, in order to avoid the lowering of the clear water level of the flume.

The sediment material used consists of a polyurethane powder that has a particle density of $\rho_{s}=1160 \mathrm{~kg} / \mathrm{m}^{3}$, characteristic diameters of $d_{10}=66.5 \mu \mathrm{m}, d_{50}=140 \mu \mathrm{m}$ and $d_{90}=214 \mu \mathrm{m}$, where $d_{\mathrm{x}}$ represents the grain size diameter for which $\mathrm{x} \%$ of the sediments have smaller diameters. The settling velocity of the $d_{50}$ diameter is $v_{s}=1.5 \mathrm{~mm} / \mathrm{s}$ and is considered to be the representative settling velocity of the material.

\subsection{Experimental measurements}

Several parameters are measured throughout the experiments:

- Discharges are measured using three electromagnetic flowmeters. One is placed at the pumping pipe (Fig. 1) to measure the inflow discharge $Q_{T C}$ of the turbidity current. A second one is placed at the venting pipe (Fig. 1) to measure the outflow discharge $Q_{V E N T}$ used for venting. Finally, a third flowmeter is placed at the recirculation pipe (Figs. 1 and 3). The latter measures the discharge of clear water pumped from the downstream compartment to the main flume $Q_{R E S}$. In the range of the discharge values used, the accuracy of the flowmeters is estimated at $\pm 0.6 \%$ (Endress + Hauser, Switzerland).

- Concentrations are measured using two SOLITAX sc turbidity probes. One is placed at the head tank and the other one at the exit of the venting pipe. These probes measure turbidity values in FNU. Through a calibration procedure, turbidity is converted into concentration values in $\mathrm{g} / \mathrm{l}$. Concentrations of the turbidity current inflow $C_{T C}$ and the vented current $C_{V E N T}$ are measured with an accuracy of around $1 \%$.

- Water levels are measured using two ultrasonic level probes placed in the head tank and in the main flume. Levels are kept constant and equal in order to ensure that there are no fluxes between the clear water of the main flume and the mixture of the head tank, which could dilute the latter, reduce its concentration, and affect the inflow discharge. The accuracy of this instrument is around $\pm 0.5 \mathrm{~mm}$ (Baumer, Switzerland).

- Velocity profiles are measured at different locations (i.e., $2.8 \mathrm{~m}$, $4.1 \mathrm{~m}, 5.5 \mathrm{~m}, 5.8 \mathrm{~m}, 6.0 \mathrm{~m}$, and $6.2 \mathrm{~m}$ from the inlet) in the main 


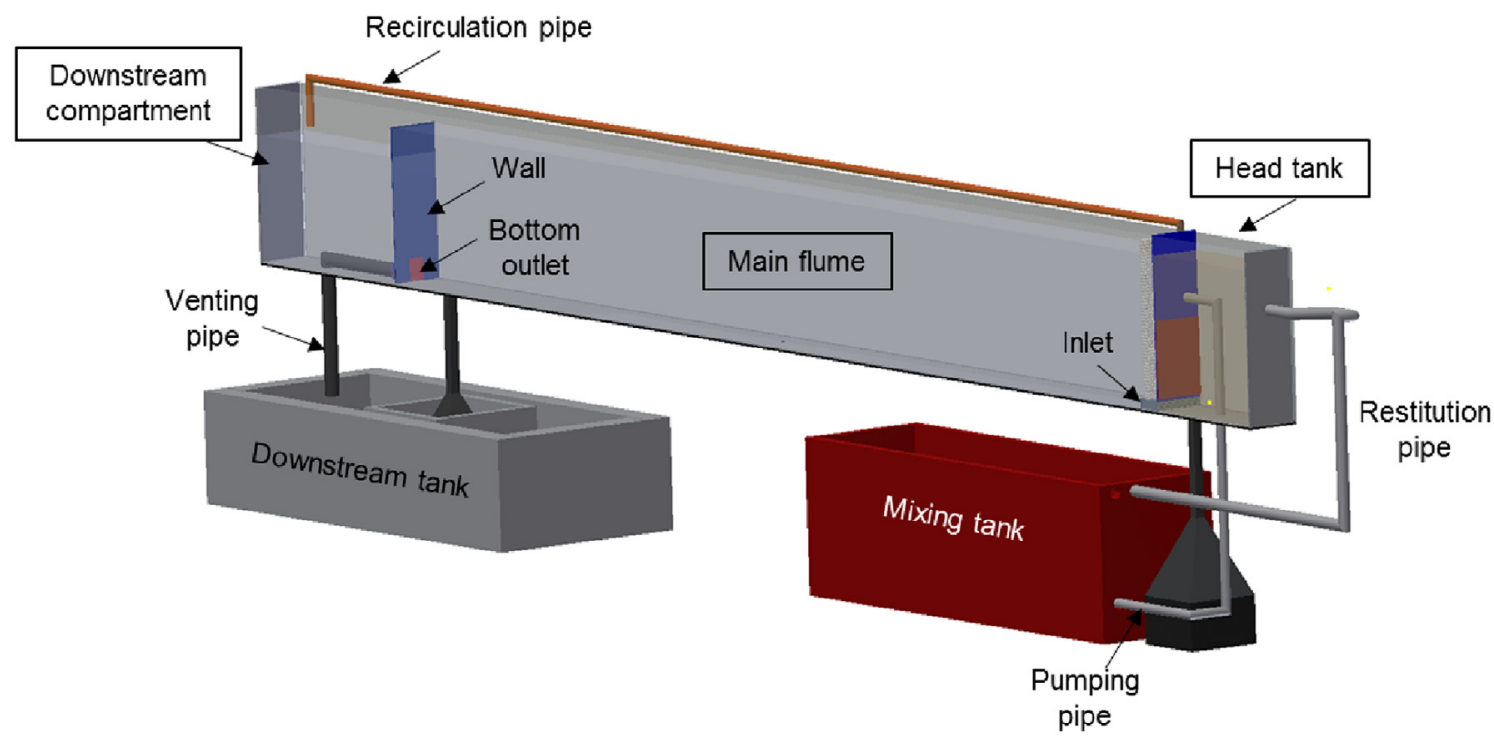

Fig. 1. Schematic view of the experimental set-up used to generate and vent turbidity currents.

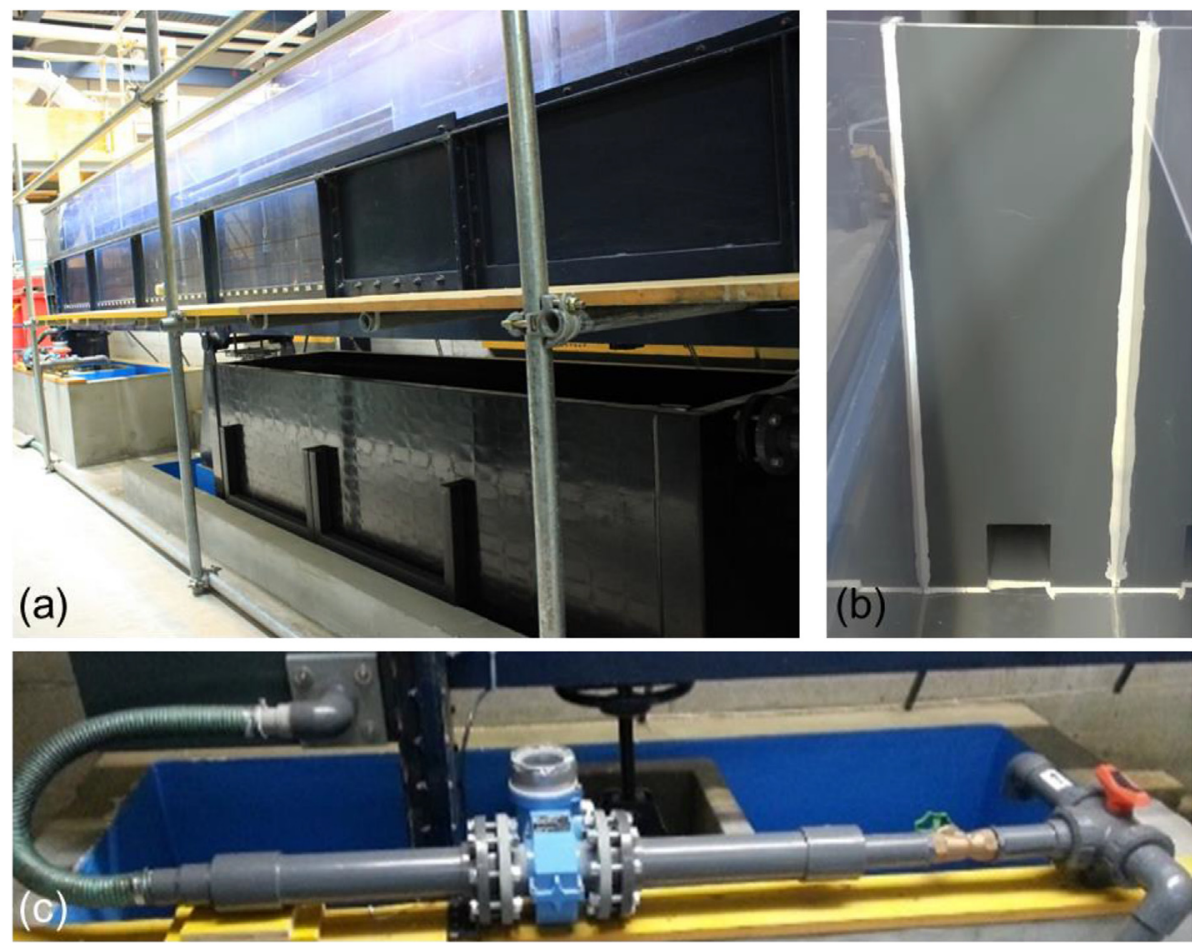

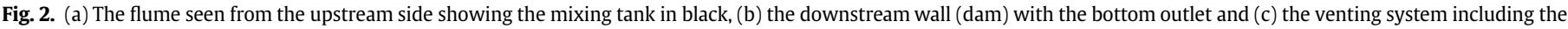
flowmeter, discharge control valves and downstream tank.

flume using Ultrasonic Velocity Profilers (UVP, Metflow, Switzerland). The emitting frequency is $4 \mathrm{MHz}$. The sampling period of the UVP is $38 \mathrm{~ms}$ per profile. The main source of error can be due to a misalignment of the transducers. The error in the inclination was estimated by Oehy (2003) who used the same type of UVP mount, as less than $0.5^{\circ}$ corresponding to $\pm 3 \%$ of velocity error.

- Deposition is measured along the flume using an electrical resistance-based depositometer (ERBD) which converts electrical resistance into deposited quantities (mass or thickness). The theoretical details and calibration procedure can be found in
De Rooij et al. (1999), Oehy (2003) and Chamoun et al. (2016c). Deposition is measured in space and time at 62 fixed points of the main flume. An error analysis (Chamoun et al., 2016c) showed that the total error that can affect the measured thickness of the deposit is around $0.06 \mathrm{~mm}\left(\approx d_{10}\right)$.

- Temperatures are measured in the head tank and in the main flume before and after the tests for two main reasons: (1) during the tests, these two temperatures should be close enough to keep the density difference solely due to the presence of suspended particles. The average temperature difference of the considered tests is $2.5{ }^{\circ} \mathrm{C}$, which corresponds to a density 

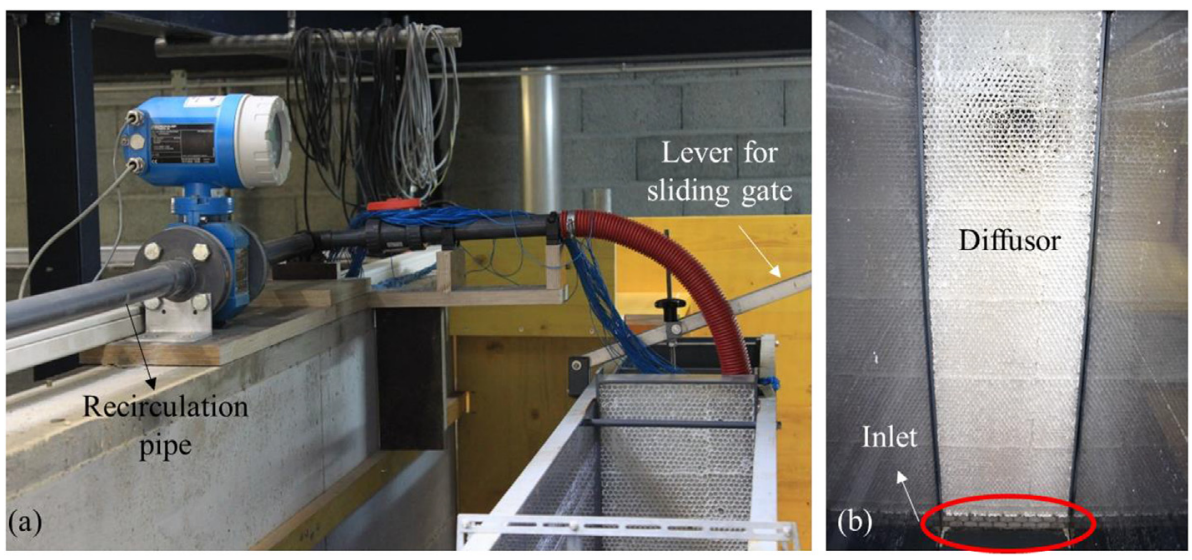

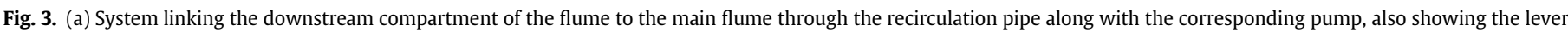
used to open/close the sliding gate; (b) the inlet and the diffusor above it seen from the downstream side of the sliding gate.

difference of $0.00025 \mathrm{~g} / \mathrm{cm}^{3}$, equivalent to only $7 \%$ of the density difference due to the suspended sediments; (2) the value of the electrical resistance measured by the ERBD not only depends on the layer thickness but also on the water temperature in the main flume which is needed for the calculation of the deposition values.

- Videos and photos of the tests are obtained using a camera placed $1.5 \mathrm{~m}$ facing the flume. The resolution of the video recordings is $1080 \mathrm{p}=1980 \times 1080$ pixels.

Measurement acquisition frequency of the electromagnetic flowmeters, ultrasonic level probes, ERBD, and turbidity probes is around $2.75 \mathrm{~Hz}$ corresponding to a time step of $0.36 \mathrm{~s}$.

\section{Experimental procedure}

At the beginning of a test, sediment material was added to clear water in the mixing tank until reaching the fixed concentration value $C_{T C}$ defined for the test. Meanwhile, the main flume was filled with clear water up to a level of $80 \mathrm{~cm}$ (at the downstream wall) when using the $0 \%$ and $2.4 \%$ slopes and a level of $92 \mathrm{~cm}$ (at the downstream wall) when using the $5.0 \%$ slope. Once the mixture was ready and the main flume filled with clear water, the watersediment mixture was pumped from the mixing tank into the head tank through the pumping pipe. It was then spilled back into the mixing tank using the restitution pipe and was therefore mixed between both tanks. This process lasted for a few minutes until the mixture was judged homogeneous and the measured concentration at the head tank reached the expected value for the test. At that moment, the valve of the restitution pipe was closed and the sliding gate was opened. Therefore, the pumped mixture from the mixing tank directly reached the main flume through the inlet. Due to density difference, a turbidity current is generated inside the main flume. The turbidity current was continuously-fed with a constant inflow discharge $Q_{T C}$ and concentration $C_{T C}$. The current advanced along the main flume until reaching the wall/bottom outlet at which point it was vented by applying an outflow discharge $Q_{V E N T}$ through the bottom outlet. The evacuated current then reached the downstream tank where outflowing concentration measurements $C_{\text {VENT }}$ were taken.

\subsection{Experimental conditions}

Three main parameters are evaluated: (1) the bed slope and (2) the outflow discharge. Three different bed slopes are tested: a horizontal bed (0\%), slopes of $2.4 \%\left(1.4^{\circ}\right)$ and $5.0 \%\left(2.9^{\circ}\right)$. For each slope, the venting degree $\Phi=Q_{V E N T} / Q_{T C}$, defined as the ratio between the outflow discharge $Q_{V E N T}$ and the discharge of the inflowing turbidity current $Q_{T C}$ was varied and the efficiency of venting was evaluated. Three series of tests (i.e., E0, E1 and E2 in Table 1) each corresponding to one bed slope are considered. Due to the high frequency of measurements, the influence of the duration of venting could be also assessed.

Table 1 provides the inflow and outflow boundary conditions of the tests. $C_{T C}$ is the initial concentration of the inflowing turbidity current, $\rho_{t 0}$ is the initial density of the turbidity current, $g_{0}^{\prime}=g C_{T C}$ $\left(\left(\rho_{s}-\rho_{w}\right) / \rho_{w}\right)$ (where $g$ is the gravitational acceleration and $\rho_{w}$ the density of the clear water) is the initial reduced gravity of the current, and $B_{0}=g_{0}^{\prime} q_{T C}$ (where $q_{T C}$ is the initial specific discharge of the current) is the initial buoyancy flux of the turbidity current (Graf and Altinakar, 1995).

In order to reduce the effect of turbidity currents dynamics on the results of venting efficiencies and focus on the effect of bed slope and outflow discharge, the turbidity currents' inflow concentration and discharge are not varied. In the following, the steadiness of inflow concentration and discharge as well as outflow discharges are checked. The results include all the tests:

- On average, the initial concentration of the turbidity currents (Table 1) is $C_{T C}=25 \mathrm{~g} / \mathrm{l}$ (volumetric concentration of $2.1 \%$ ). For a single test, the average standard deviation of inflow concentration is $1.9 \mathrm{~g} / \mathrm{l}$ while the standard deviation of the concentrations between the tests is $2.6 \mathrm{~g} / \mathrm{l}$. The initial concentration of turbidity currents was thus sufficiently steady throughout the tests.

- The initial turbidity current discharge is of $1 \mathrm{l} / \mathrm{s}$ on average for all the tests. For a single test, the average standard deviation of the turbidity current discharge is $Q_{T C}=6 \times 10^{-3} \mathrm{l} / \mathrm{s}$, and the standard deviation between the tests is $9 \times 10^{-3} \mathrm{l} / \mathrm{s}$. Thus, steady inflow discharges were also ensured at the inlet.

- The standard deviation of the outflow discharge averaged on all the tests is $0.01 \mathrm{l} / \mathrm{s}$, representing only $3.6 \%$ of the smallest tested outflow discharge $(0.3 \mathrm{l} / \mathrm{s})$. Constant outflow conditions were accomplished during the tests.

- Water level differences between the head tank and the main flume during the tests are of $9 \mathrm{~mm}$ on average, representing $0.8 \%$ of the maximum water depth (the latter is $80 \mathrm{~cm}$ for the $2.4 \%$ slope and the horizontal bed and $92 \mathrm{~cm}$ for the $5.0 \%$ slope). 
Table 1

Characteristics of the inflow and outflow boundary conditions of the generated turbidity currents.

\begin{tabular}{|c|c|c|c|c|c|c|c|c|}
\hline \multirow[t]{2}{*}{ Test No. } & \multirow[t]{2}{*}{$S(\%)$} & \multicolumn{6}{|c|}{ Inflowing turbidity current } & \multirow{2}{*}{$\frac{\text { Venting degree } \Phi}{Q_{V E N T} / Q_{T C}(\%)}$} \\
\hline & & $C_{T C}(\mathrm{~g} / \mathrm{l})$ & $\rho_{t 0}\left(\mathrm{kgm}^{-3}\right)$ & $g_{0}^{\prime}\left(\mathrm{cms}^{-2}\right)$ & $B_{0}\left(\mathrm{~cm}^{3} \mathrm{~s}^{-3}\right)$ & $Q_{V E N T}(\mathrm{l} / \mathrm{s})$ & $Q_{T C}(1 / s)$ & \\
\hline E0.1 & 0.0 & 27.6 & 1003.5 & 3.74 & 143.1 & 0.31 & 1.04 & 30 \\
\hline E0.2 & 0.0 & 26.0 & 1003.3 & 3.53 & 130.8 & 0.52 & 1.01 & 50 \\
\hline E0.3 & 0.0 & 28.4 & 1003.6 & 3.86 & 139.2 & 0.66 & 0.98 & 65 \\
\hline E0.4 & 0.0 & 27.0 & 1003.4 & 3.66 & 139.0 & 0.85 & 1.03 & 80 \\
\hline E0.5 & 0.0 & 29.4 & 1003.7 & 3.99 & 151.3 & 1.01 & 1.03 & 100 \\
\hline E0.6 & 0.0 & 25.5 & 1003.2 & 3.46 & 127.1 & 1.16 & 1.00 & 115 \\
\hline E0.7 & 0.0 & 23.0 & 1002.9 & 3.12 & 115.8 & 1.26 & 1.01 & 125 \\
\hline E1.1 & 2.4 & 21.1 & 1002.6 & 2.86 & 103.4 & 0.30 & 0.98 & 30 \\
\hline E1.2 & 2.4 & 28.4 & 1003.6 & 3.86 & 142.8 & 0.50 & 1.01 & 50 \\
\hline E1.3 & 2.4 & 28.4 & 1003.6 & 3.86 & 142.1 & 0.64 & 1.00 & 65 \\
\hline E1.4 & 2.4 & 22.1 & 1002.7 & 3.00 & 110.0 & 1.06 & 1.00 & 100 \\
\hline E1.5 & 2.4 & 25.1 & 1003.1 & 3.40 & 123.7 & 1.34 & 0.99 & 135 \\
\hline E1.6 & 2.4 & 26.0 & 1003.3 & 3.53 & 130.0 & 1.55 & 1.00 & 155 \\
\hline E1.7 & 2.4 & 25.1 & 1003.2 & 3.41 & 124.6 & 1.97 & 0.99 & 200 \\
\hline E2.1 & 5.0 & 28.7 & 1003.6 & 3.89 & 143.3 & 0.51 & 1.00 & 50 \\
\hline E2.2 & 5.0 & 21.0 & 1002.6 & 2.83 & 105.2 & 0.67 & 1.01 & 65 \\
\hline E2.3 & 5.0 & 26.2 & 1003.3 & 3.56 & 132.8 & 1.03 & 1.01 & 100 \\
\hline E2.4 & 5.0 & 25.0 & 1003.1 & 3.39 & 123.0 & 1.34 & 0.99 & 135 \\
\hline E2.5 & 5.0 & 23.5 & 1002.9 & 3.19 & 119.9 & 1.55 & 1.02 & 155 \\
\hline E2.6 & 5.0 & 21.8 & 1002.7 & 3.0 & 108.1 & 2.01 & 0.99 & 200 \\
\hline
\end{tabular}

\subsection{Analysis concept}

The principal goal of this work is to investigate the influence of the venting degree and bed slopes on the sediment release efficiency of venting. Nevertheless, before discussing the venting efficiency, the generated turbidity currents are characterized in terms of velocity, rate of turbulence and deposition, in order to provide a better understanding of the type and dynamics of the turbidity currents under study, particularly when it comes to scaling up the results. The efficiency of venting is analyzed based on two different definitions: the local venting efficiency (LVE) using only sediment masses and the venting efficiency indicator (VEI) combining sediment masses with water losses. The two definitions are time integrals and can thus be evaluated all along the duration of the venting operation:

- The $L V E$ represents the ratio between (1) the total mass of sediments vented starting the beginning of venting $\left(t=T_{v i}\right)$ and until the end of the operation $\left(t=T_{v f}\right): \int_{t=T_{v i}}^{T_{v f}} C_{V E N T} Q_{V E N T} \mathrm{~d} t$ and (2) the total mass of inflow sediments from which the total mass of deposited sediments is subtracted: $\int_{t=T_{v i}}^{T_{v f}} C_{T C} Q_{T C} \mathrm{~d} t-\int_{t=T_{v i}}^{T_{v f}} \dot{m}_{d e p} \mathrm{~d} t$ where $\dot{m}_{d e p}$ is the deposited sediment mass flow rate. The deposited mass is subtracted since venting does not induce retrogressive erosion and deposited sediments are not likely to be evacuated.

- The VEI consists on multiplying the LVE by a global volumetric concentration defined by the ratio between the total volume of sediment vented and the total volume of clear water released during venting: $\operatorname{LVE}\left(\int_{t=T_{v i}}^{T_{v f}} V_{V E N T s e d} \mathrm{~d} t / \int_{t=T_{v i}}^{T_{v f}} V_{V E N T w a t} \mathrm{~d} t\right)$.

Using these equations, the LVE and the VEI can be calculated punctually at a specific time of the test $t$ after the beginning of venting, or they can be assessed in time by calculating the integrals at each measuring time step until $t=T_{v f}$. The most favorable scenario is considered to be the one leading to the highest sediment mass evacuated with the smallest water loss possible. Additionally, in the aim of offering an analogy with prototype cases, a normalized duration of venting was proposed, the quasi-steady state was averaged and used to reach a normalized duration of venting expressed by $\bar{t}=\left(t-T_{v i}\right)^{2} g_{a p p}^{\prime} / h_{L}$ where $g_{a p p}^{\prime}$ is the reduced gravitational acceleration of the current while approaching the bottom outlet and $h_{L}$ is the height of aspiration reached by the outlet to evacuate sediments approaching it (Craya, 1949; Fan, 1960; Gariel, 1949). These definitions were initially introduced and detailed in a previous publication (Chamoun et al., 2017). All equations corresponding to the above mentioned concepts can be found in the appendix attached to the present article.

\section{Results and discussion}

\subsection{Development of the front and head of the turbidity current}

Using the video recordings, the size of the turbidity current's head was assessed for each of the three slopes. All the tests performed on the same slope were considered and the values of $H_{\text {head }}$ observed at a specific distance $x$ from the inlet were averaged between the different tests. This calculation was repeated for eight different positions $x$ (corresponding to the 8 points by slope in

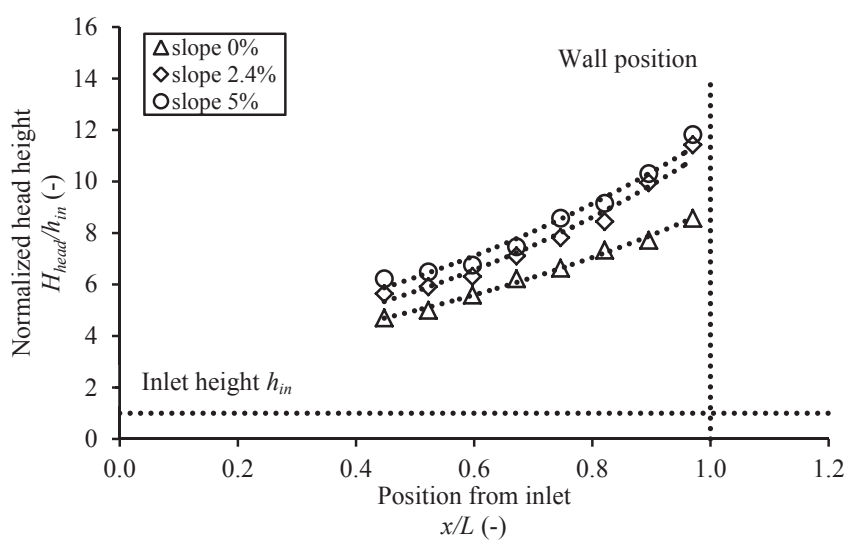

Fig. 4. Evolution of the normalized head height Hhead/hin of the turbidity current as a function of the relative position $x / L$ of the current in the flume for the different bed slopes. 
Fig. 4).

Fig. 4 shows the development of the head size of the current $H_{\text {head }}$, normalized by the height of the inlet $h_{\text {in }}=0.045 \mathrm{~m}$. It is plotted relatively to the position $x$ of the current's head from the inlet which is normalized by the length of the main flume $L=6.7 \mathrm{~m}$. Note that the observations start only at $x / L \approx 0.44$ because of the presence of a metallic wall as part of the flume's structure before that distance (Fig. 2(a)).

The head of the turbidity current increases with distance and with increasing slopes. In fact, the higher the slope, the higher the clear water entrainment, which causes the increase of the size of the head. However, with a horizontal bed, the head increases more or less linearly with distance from the inlet. For the $2.4 \%$ and $5.0 \%$ slopes, starting $x / L \approx 0.8$, the current's head seems to develop exponentially while approaching the wall. A closely similar behavior was observed by Lee and Yu (1997) who also described an exponential increase in the head height of turbidity currents with distance. However, in their case the inlet was represented by a stable plunge point and the increase of head height was preceded by a decrease due to different dynamics involved during the formation of the turbidity current at the plunge point.

In Fig. 5, the rate of increase of $H_{\text {head }}$ in space, $\mathrm{d} H_{\text {head }} / \mathrm{d} x$ was averaged for each slope based on the data in Fig. 4 and plotted relatively to the bed slope. The results from this study (values are shown in brackets in Fig. 5) are compared with the ones obtained by Britter and Linden (1980) for saline currents which were extrapolated by Altinakar et al. (1990) leading to $\mathrm{d} H_{\text {head }} / \mathrm{d} x=0.23 \alpha$ (in radian). The latter is valid for saline currents and for $5^{\circ} \leq$ $\alpha \leq 90^{\circ}$. However, Altinakar et al. (1990) concluded based on their data that turbidity currents' head grew faster than saline currents'. A comparison between the data of Britter and Linden (1980) and those of the present study also lead to the same conclusion (Fig. 5). Also, on a horizontal bed $\left(\alpha=0^{\circ}\right), \mathrm{d} H_{\text {head }} / \mathrm{d} x \neq 0$ for turbidity currents, unlike for saline currents where the head's size does not increase with the distance $\left(\mathrm{d} H_{\text {head }} / \mathrm{d} x=0\right)$ on a horizontal bed. This explains the shift between the two lines of Fig. 5 .

In the following, front velocity values are obtained by progressively considering two different positions of the turbidity current's head in the flume and noting the duration spent by the current to travel from the first position to the second. Then, the velocity is calculated and corresponds (in the plot of Fig. 6) to the point located halfway between the two positions considered. The front velocity $U_{f}$ at a specific location was averaged for all the tests performed using the same slope. In fact, the characteristics of the turbidity currents were similar and thus their front velocities were

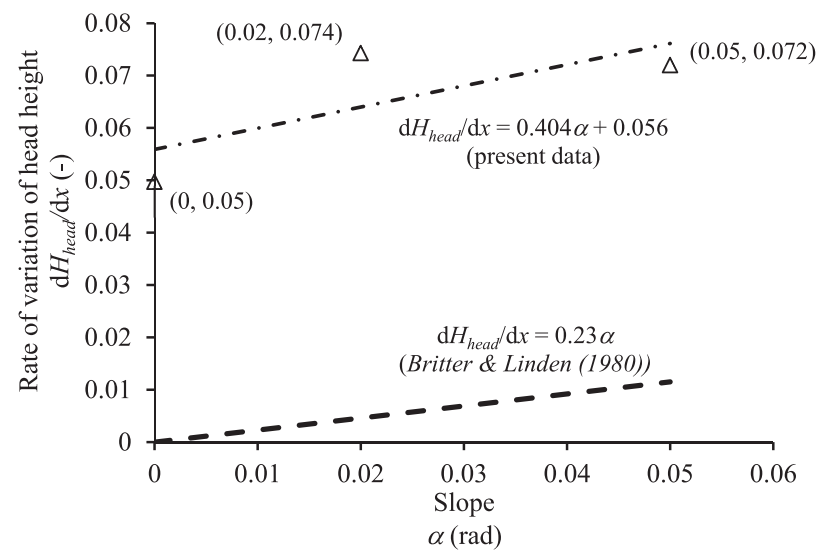

Fig. 5. Increase rate of the head height of a turbidity current $\mathrm{d} H_{\text {head }} / \mathrm{d} x$ as a function of the slope compared to that of a saline current as found by Britter and Linden (1980).

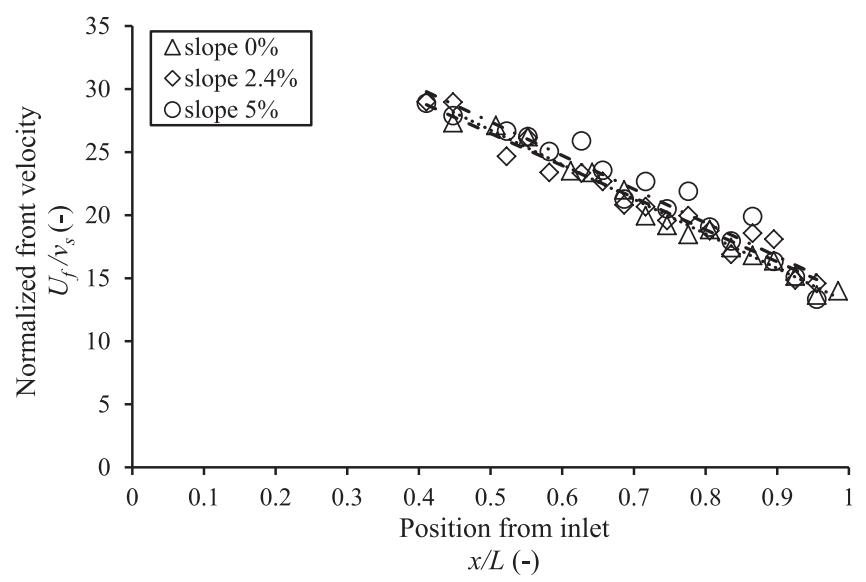

Fig. 6. Normalized front velocity $U_{f} / v_{s}$ of the turbidity currents as a function of the relative position $x / L$ of the current in the flume for the different bed slopes.

also similar when considering the same slope. The fluctuation (standard deviation) of the front velocity around the average when considering all tests is of $13 \%$. The average values are thus representative. In Fig. 6, the front velocity normalized by the settling velocity of the material $v_{s}$ is plotted as a function of the normalized position $x / L$ for the different slopes. In the three cases, turbidity currents decelerate with more or less the same rate. In fact, the increase in the head size with increasing slopes (Fig. 4) suggests high water entrainment. Therefore, despite the fact that the gravity acceleration component parallel to the slope is increasing with the slope and is thus expected to accelerate the current, it is being counterbalanced by water entrainment. This leads to quasi-similar front velocities for the three slopes.

\subsection{Body velocity}

Using the UVP transducers (see section 2.1), velocity profiles of the turbidity currents are obtained at different positions in the main flume (i.e., $2.8 \mathrm{~m}, 4.1 \mathrm{~m}, 5.5 \mathrm{~m}, 5.8 \mathrm{~m}, 6.0 \mathrm{~m}$, and $6.2 \mathrm{~m}$ from
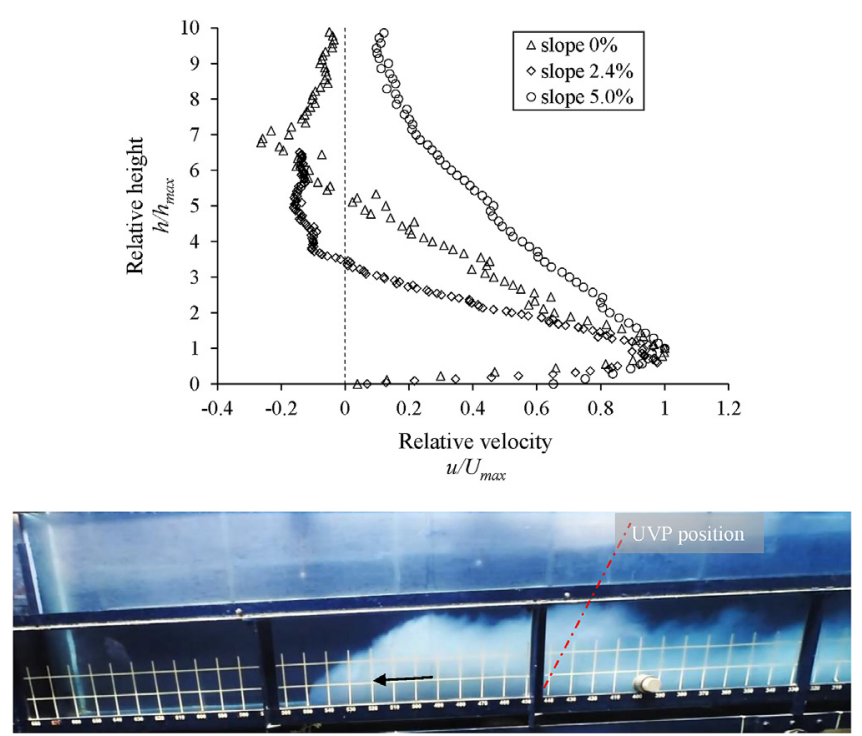

Fig. 7. Average velocity profiles of the turbidity currents $u / U_{\max }$ at $4.1 \mathrm{~m}$ from the inlet for the different slopes and a photo of the turbidity current flowing on the $5.0 \%$ slope, highlighting the part of the current where the velocity plots are considered. The grid on the channel is $10 \times 10 \mathrm{~cm}^{2}$. 
the inlet). For all the cases, the profiles taken at the head of the current (3D velocity fields) are discarded and only the profiles in the body are considered. The profiles at $x=4.1 \mathrm{~m}$ from the inlet were chosen to represent the turbidity current's velocity. An average profile was calculated for each slope. Fig. 7 shows the velocity $u$ normalized by the maximum velocity of each profile $\left(U_{\max }\right)$ along the measuring height $h$ normalized by $h_{\max }$ corresponding to $U_{\text {max }}$. Using Turner's equations (Ellison and Turner, 1959), the representative velocity $U$ and height $H$ of the currents are calculated for the three slopes. Based on these data, the bulk Richardson number can be concluded $R i=\left(g^{\prime} H \cos \alpha\right) / U^{2}$ where $g$ ' is the estimated reduced gravity at $x=4.1 \mathrm{~m}$. Consequently, the Froude number $F r=1 / R i^{0.5}$ could be estimated. The currents are subcritical on the $0 \%$ and $2.4 \%$ slopes and slightly supercritical on the $5.0 \%$ slope. Additionally, the Reynolds number was calculated as $\mathrm{Re}=$ $U H / \nu$ where $\nu$ is the kinematic viscosity of water. Table 2 provides a summary of the above mentioned parameters. The values presented are averages of all the tests performed using the same slope.

The turbidity currents encountered in reservoirs are commonly highly turbulent; similar Reynolds numbers are hardly achievable in laboratory. However, for all the cases, Re $>2000$ suggesting that all the turbidity currents generated are fully turbulent (Kneller and Buckee, 2000). Thus, the Froude number similarity can be applied and the results can be scaled up to prototype.

\subsection{Deposition}

The total mass of sediment deposited along the flume right before opening the outlet (at the arrival of the current to the wall) $M_{\text {deptot }}$ is compared to the total sediment mass of the inflowing turbidity current $M_{\text {intot }}$ for the three different slopes. Table 3 shows a slight increase of the deposited mass with increasing slopes. In fact, as mentioned previously, higher slopes yield a higher water entrainment which results in a higher dilution of the current, thus the density difference $\Delta \rho=\rho_{t}-\rho_{w}$ between the turbidity current $\left(\rho_{t}\right)$ and the clear water $\left(\rho_{w}\right)$ decreases. Consequently, the reduced gravitational acceleration $g^{\prime}=g\left(\Delta \rho / \rho_{w}\right)$ decreases leading to the decrease of the buoyancy of the current. The latter represents the ability of the current to keep sediments in suspension. All this results in quite similar or higher deposition when increasing slopes from the horizontal position. In fact, the tested slopes are too small to impose a sustainable increase in the buoyancy, which could potentially lead to a higher capacity of suspending sediments. The type and settling velocity of the sediments used are most probably the main reason for this behavior.

\subsection{Normalized outflow concentration}

Once the current reaches the bottom outlet to be vented, part of the current is reflected and another part is obstructed by the wall forming a muddy lake. Thus, when venting is applied, the evacuated flow depends on the dynamics and density of the muddy lake in its vicinity.

In the following, the outflow concentration $C_{V E N T}$ was normalized by the inflow concentration $C_{T C}$. Fig. 8 shows an example of the variation of the normalized outflow concentration $C_{V E N T} / C_{T C}$ as a

\section{Table 2}

Characteristics of turbidity currents on different slopes: velocity and height, Richardson number, Froude number and Reynolds number.

\begin{tabular}{llllll}
\hline$S(\%)$ & $U(\mathrm{~cm} / \mathrm{s})$ & $H(\mathrm{~cm})$ & $R i$ & $F r$ & $\operatorname{Re}\left(10^{3}\right)$ \\
\hline 0.0 & 2.23 & 23.89 & 11.51 & 0.29 & 4.87 \\
2.4 & 3.52 & 18.77 & 2.73 & 0.60 & 6.60 \\
5.0 & 5.08 & 13.91 & 0.97 & 1.02 & 7.07 \\
\hline
\end{tabular}

Table 3

Percentage of deposited mass compared to inflowing mass for the different slopes.

\begin{tabular}{ll}
\hline$S(\%)$ & $M_{\text {deptot }} / M_{\text {intot }}(\%)$ \\
\hline 0.0 & 68 \\
2.4 & 71 \\
5.0 & 80 \\
\hline
\end{tabular}

function of the duration of venting $t-T_{v i}$, where $t$ is the duration of the test $(t=0$ corresponds to the time at which the gate is opened and the current is triggered) and $T_{v i}$ is the time at which venting starts (corresponding to the arrival of the turbidity current at the outlet), for the case of $\phi=50 \%$. Note that the value of $t=T_{v i}$ is not the same for all tests since the exact moment at which the current reaches the outlet and venting starts is slightly different between the tests. During the analysis, the determination of the value of $T_{v i}$ is done by noting the time $t$ at which $Q_{V E N T}>0$.

Increasing slopes generally resulted in higher outflow concentrations. However, this variation is much clearer when moving from the horizontal bed to the $2.4 \%$ slope than moving from the slope of $2.4 \%-5.0 \%$. $C_{V E N T} / C_{T C}$ is around $9 \%$ for the horizontal bed and between $11 \%$ and $12 \%$ for the $2.4 \%$ and $5.0 \%$ slopes respectively. Thus, for all the cases, there is a dilution of the current before reaching the bottom outlet, due to deposition. Based on the results of the outflow concentrations obtained for the three different slopes, it can be concluded that the trend of concentrations can be divided into two phases, starting with an increase of concentrations until reaching a quasi-steady state.

Fig. 9 shows the muddy lake after a duration of venting of $t$ $T_{v i}=260 \mathrm{~s}$, for the horizontal bed and for the $5.0 \%$ slope. The photos in Fig. 9 show that by increasing the bed slope, the turbidity current is less reflected and the muddy lake that is formed is thus more concentrated. With a horizontal bed, the reflected turbidity current could reach large distances upstream while for the $5.0 \%$ slope, the suspended sediments did not spread much further than around $2 \mathrm{~m}$ from the wall. Other research studies investigated the reflection of turbidity and saline currents, particularly in terms of deposition (e.g., De Rooij and Dalziel, 2009; Kneller et al., 1991). However, it was mostly for lock-exchange triggers unlike the present case.

\subsection{Venting efficiency}

The concepts described in section 3.2 are used henceforth. As a first analysis, the efficiency of venting was evaluated based on the $L V E$, calculated for each slope after a specific duration of venting (Fig. 10). In fact, venting did not last for the same duration for the different tests. Therefore, a common duration was determined for each slope based on the shortest test, for comparison purposes. Notably, for the horizontal bed ( $S=0 \%$ ), the shortest (common) duration of venting was $t-T_{v i}=212 \mathrm{~s}$; for $S=2.4 \%$, this duration was $t-T_{v i}=190 \mathrm{~s}$ and for $S=5.0 \%, t-T_{v i}=127 \mathrm{~s}$. In Fig. $10, L V E$ values are highlighted for cases where increasing the venting degree is the least efficient. For the horizontal bed, $\phi=100 \%$ and $\phi=115 \%$ result in closely similar values of efficiency. For the $2.4 \%$ and $5.0 \%$ slopes, the efficiencies obtained with $\phi=135 \%$ and $\phi=155 \%$ have very similar values.

This type of analysis is comparable to the type of results obtained in prototype cases where the sediment release efficiency is commonly calculated at the end of the flood or the venting operation to estimate the total amount of sediment released. However, in order to have a closer look, it is of interest to evaluate the variation of LVE as a function of time and to verify whether the tendencies of Fig. 10 are only "local in time" and dependent on the duration of venting. 


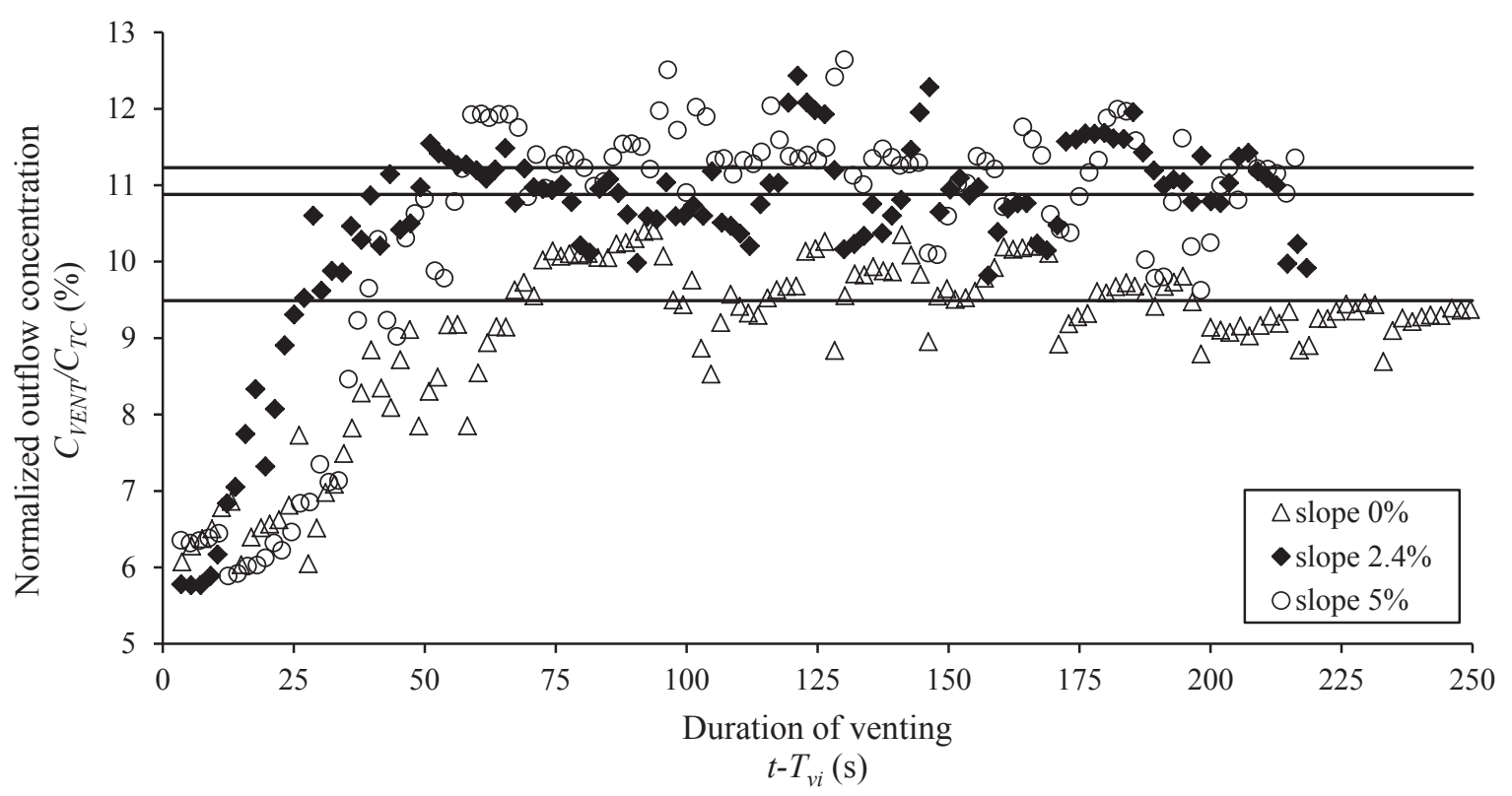

Fig. 8. Variation of the normalized outflow concentration $C_{V E N T} / C_{T C}$ as a function of the duration of venting $t-T_{v i}$ for a venting degree $\phi=50 \%$.
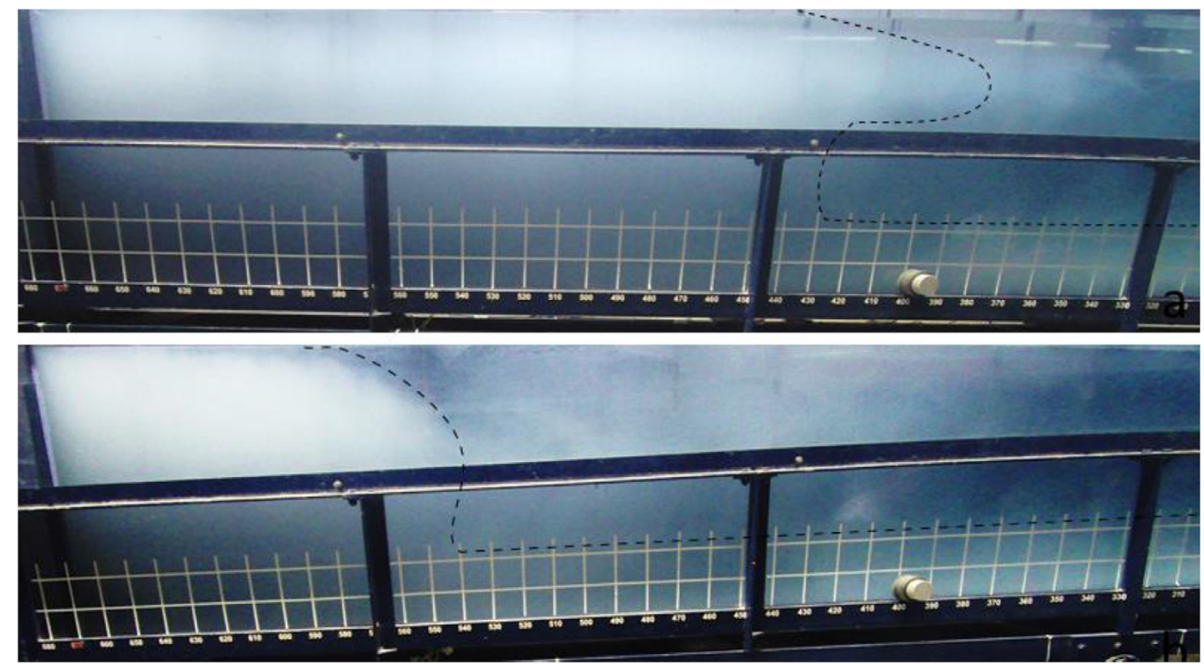

Fig. 9. Reflected turbidity current at $t-T_{v i}=260 \mathrm{~s}$ for (a) the horizontal bed and (b) the $5.0 \%$ slope.

\subsubsection{Local venting efficiency in time}

Based on previous results of LVE and VEI obtained on the horizontal bed (Chamoun et al., 2017), venting turbidity currents reached the highest efficiency for $\Phi=100 \%$. In other words, the highest sediment release was obtained with the lowest water loss for this venting degree. In the following, these parameters are assessed with the slopes of $S=2.4 \%$ and $S=5.0 \%$.

Figs. 11 and 12 show that LVE values in time increase with increasing venting degrees except when moving from $\Phi=135 \%$ to $\Phi=155 \%$ where $L V E$ values remain closely similar. This is observed for both slopes and suggests that when an outlet capacity can reach $\Phi=155 \%$ venting turbidity currents on a $2.4 \%$ or $5.0 \%$ slope should be limited to $\Phi=135 \%$. Additionally, for the $5.0 \%$ slope, a peak is observed at the beginning of venting, delaying the steady state relatively to the $2.4 \%$ slope. The steeper the slope, the less the reflection of the turbidity current at the dam and the more concentrated the muddy lake will be. The values of the peaks increase with increasing venting degrees.

However, if venting is applied with $\Phi=200 \%$, the efficiency is seen to increase again compared to that obtained with $\Phi=135 \%$. In this context, a brief analysis by Chamoun et al. (2016b) based on data from 22 Swiss dams showed that the capacity of bottom outlets is generally smaller than $200 \%$ compared to the potential flood-induced discharge of the approaching turbidity current to be vented. Therefore, it is assumed that the increased efficiency obtained for the case of $\Phi=200 \%$ is due to approaching flushing conditions more than venting conditions.

In terms of duration, the LVE values reach a steady state for almost all venting degrees and with all the slopes. The steady state lasts until the end of the tests. This duration is considered long enough to maintain steady efficiency values in time, as long as the turbidity current inflow is continuous. The experimental tests' duration can be related to prototype duration. Using the experimental height of the current $H$ and the settling velocity $v_{s}=0.15 \mathrm{~cm} /$ 


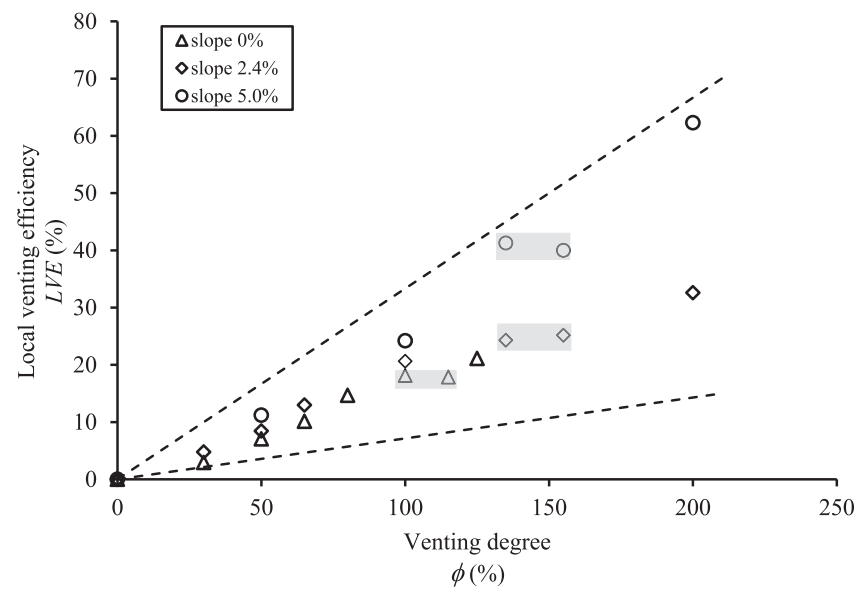

Fig. 10. Local venting efficiencies $L V E$ as a function of the venting degree $\Phi$ for a specific duration of venting fixed for different reservoir bottom slopes.

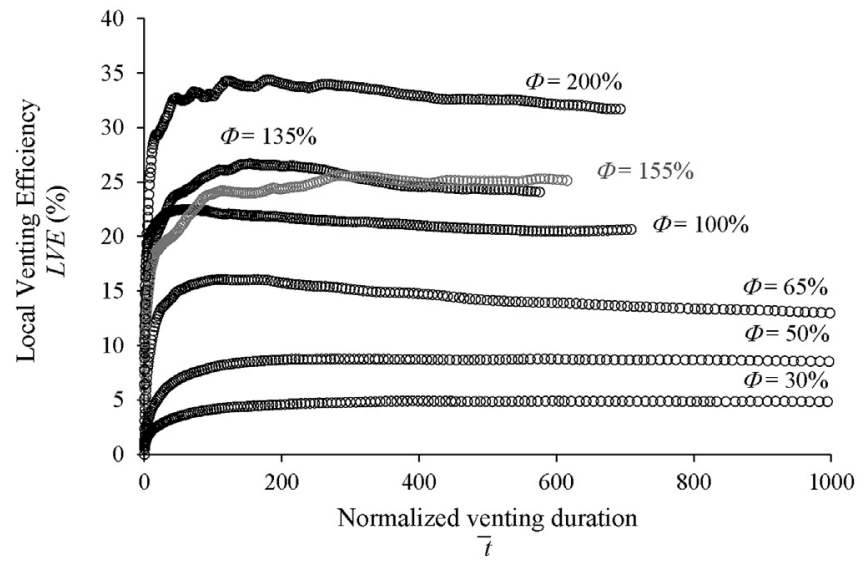

Fig. 11. Local venting efficiency $L V E$ as a function of the normalized venting duration for the different venting degrees $\Phi$ on a $2.4 \%$ slope.

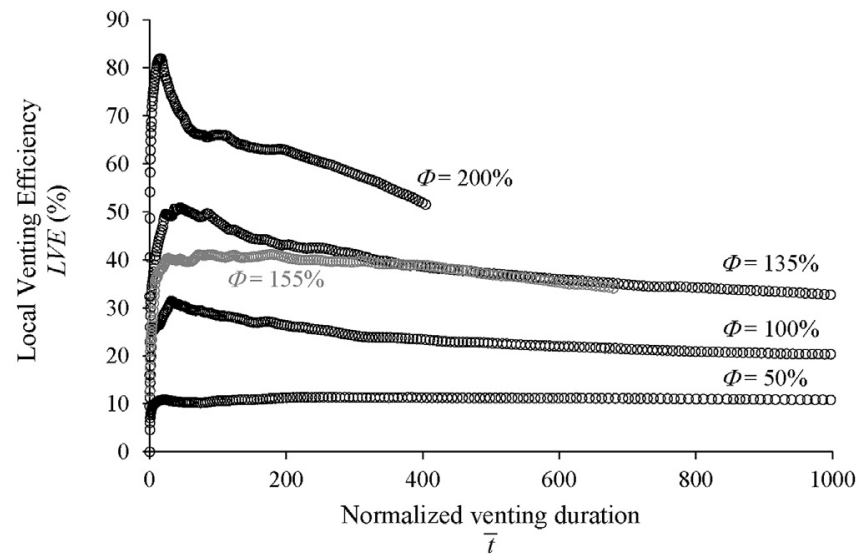

Fig. 12. Local venting efficiency $L V E$ as a function of the normalized venting duration for the different venting degrees $\Phi$ on a $5.0 \%$ slope.

s of the sediment material, an experimental "settling time" $t_{s}=H / v_{s}$ of the particles is calculated. The maximum experimental duration of venting that was tested is around $t_{\exp }=300 \mathrm{~s}$. The latter can be normalized as $t_{\exp } / t_{s}$. The value of $t_{\exp } / t_{s}$ is 2 for the horizontal bed, 2.4 for the $2.4 \%$ slope and 3.2 for the $5.0 \%$ slope. The turbidity currents found in prototype have typical heights around 5-15 m
(Nizery et al., 1952; Sinniger et al., 1994; Xu et al., 2004). Considering $H_{\text {prot }}=10 \mathrm{~m}$ with the same settling velocity $v_{s}$, the prototype settling time $t_{\text {sprot }}=H_{\text {prot }} / v_{s} \approx 6667 \mathrm{~s}$. Therefore, the venting duration of $300 \mathrm{~s}$ in the experimental time corresponds to more or less $t_{\text {prot }}=t_{\text {sprot }} \times t_{\exp } / t_{s} \approx 4-6 \mathrm{~h}$ of venting in prototype conditions.

\subsubsection{Venting efficiency indicator and water losses}

In most of the cases where venting is applied, water is in shortage and a drawdown of the reservoir's water level should be avoided. In the following, the variation in time of VEI (defined in section 3.2) which takes into account water losses is evaluated for the two upper slopes. The results (Figs. 13 and 14) confirm the conclusions obtained based on the LVE: by considering water losses, the curves corresponding to $\Phi=155 \%$ slightly drop below the ones corresponding to $\Phi=135 \%$. Additionally, with the $5.0 \%$ slope, the VEI curves for $\Phi=135 \%$ and $\Phi=200 \%$ get closer. These results suggest that an optimal venting is obtained with $\Phi=135 \%$ when using bottom outlets having a capacity up to $155 \%$ of the turbidity current's discharge $Q_{T C}$. However, in the case where the capacity of the outlet reaches $200 \%$ of the turbidity current's discharge, which is not very common, results showed that the efficiency in terms of both sediment release and water losses is the highest with $\Phi=200 \%$. This might be due to some relatively higher local erosion and the higher height of aspiration of the outlet that forces the muddy lake to stay close to the outlet.

\subsubsection{Local venting efficiency with different slopes}

The local venting efficiency in time for a specific venting degree is compared for the different slopes hereafter. Based on Figs. 15 and 16 , for the same venting degree $(\phi=50 \%$ and $\phi=100 \%$ respectively) the LVE increases with increasing slopes. It is mainly due to the behavior of the muddy lake as well as the deposition, discussed in sections 4.3 and 4.4 .

Therefore, in the range of the slopes studied in this research, which are representative of prototype slopes commonly found in the vicinity of the dam, one can conclude that a higher slope yields a higher venting efficiency. The main reason is that for higher slopes, the upstream reflection of the current at the dam decreases and the muddy lake formed has relatively high concentrations. Hence, venting should start directly after the commissioning of the dam, in order to maintain the formation of a cone in front of the low-level outlets and avoid the filling of the dead storage. The formation of the cone is guaranteed by the lower height of aspiration of the outlet. By keeping the steepest slope possible upstream of the outlet, the flattening of the bed will be avoided, thus maintaining relatively high venting efficiencies and keeping the outlet structures free of sediments.

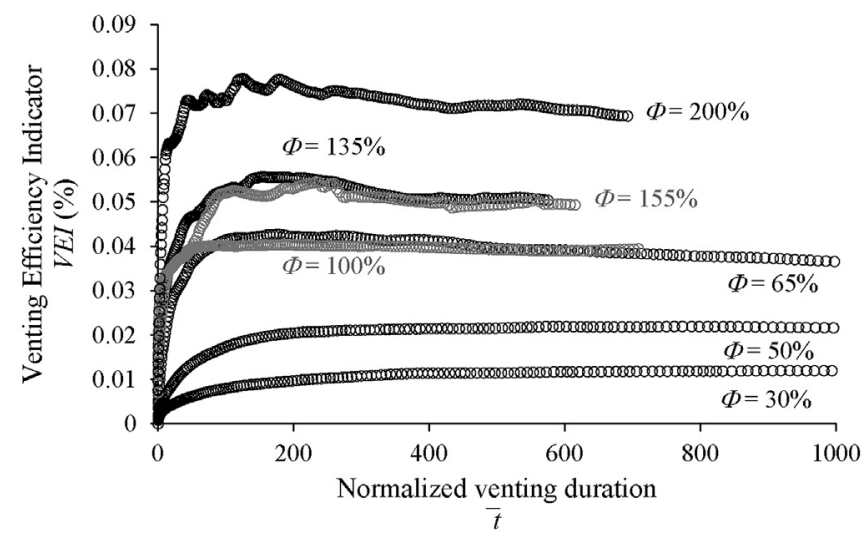

Fig. 13. Venting efficiency indicator $V E I$ as a function of the normalized venting duration for the different venting degrees $\Phi$ on a $2.4 \%$ slope. 


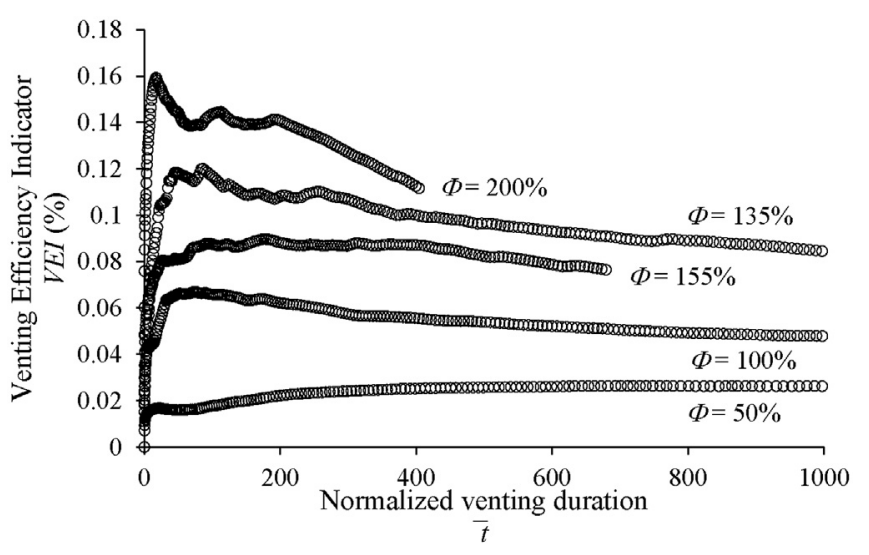

Fig. 14. Venting efficiency indicator $V E I$ as a function of the normalized venting duration for the different venting degrees $\Phi$ on a 5.0\% slope.

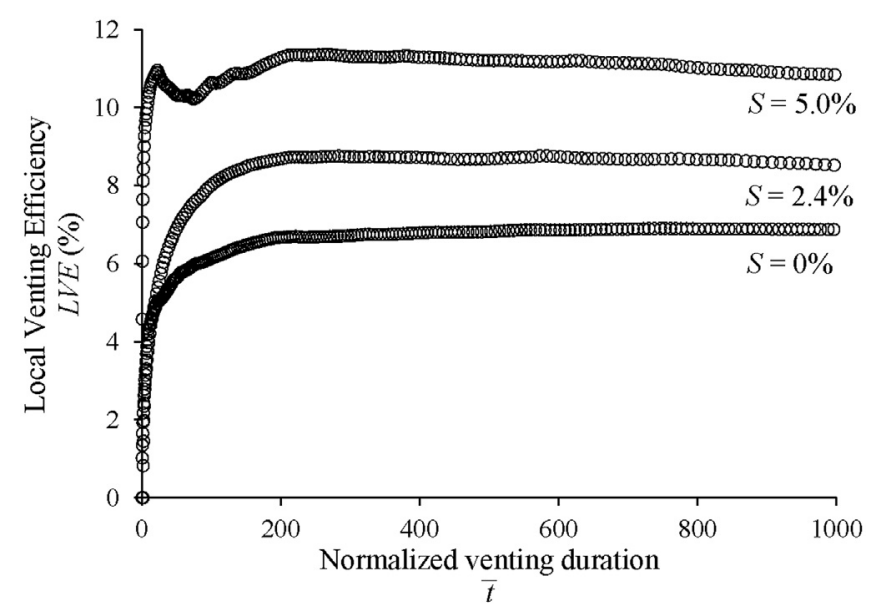

Fig. 15. Local venting efficiency $L V E$ as a function of the venting duration for a venting degree $\phi=50 \%$ for the different slopes.

\section{Conclusions}

Sedimentation of reservoirs is a critical issue causing the loss of storage capacity of reservoirs, the clogging of outlet structures, the

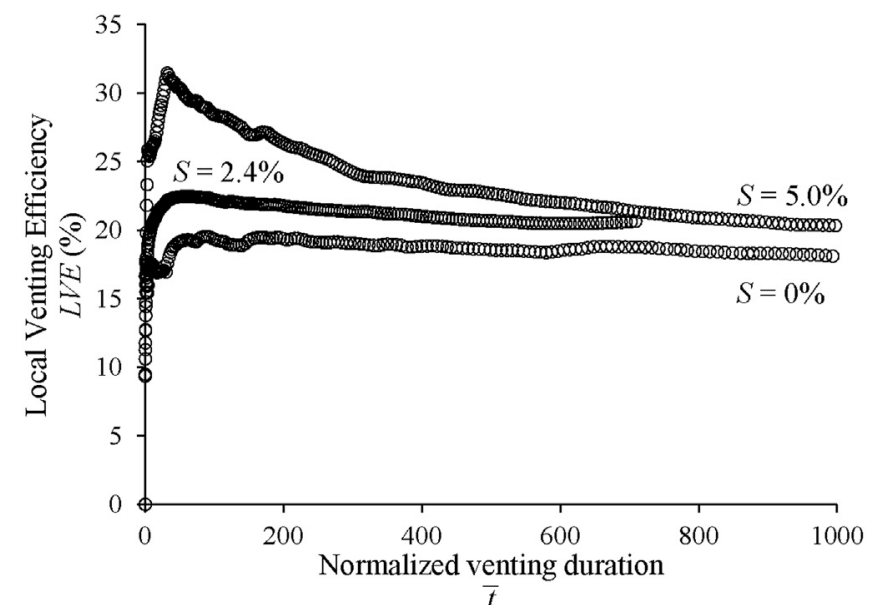

Fig. 16. Local venting efficiency $L V E$ as a function of the venting duration for a venting degree $\phi=100 \%$ for the different slopes. damage of hydraulic machinery, as well as downstream impoverishment of ecosystems. In the particular case where sedimentation is caused by turbidity currents, venting through outlets or intakes can ensure the sustainability of the storage. In the present paper, venting of turbidity currents through a bottom outlet is experimentally investigated using three different slopes (i.e., $0 \%, 2.4 \%$ and $5.0 \%)$ and applying various venting degrees defined as the ratio between outlet discharge and turbidity current discharge.

The experimental results are evaluated based on a defined local venting efficiency ( $L V E$ ) which compares the released sediment mass to the turbidity current's sediment mass from which the deposited mass is subtracted. By definition, the LVE only accounts for the duration of the inflow starting the beginning of venting. On a different note, a venting efficiency indicator (VEI), which considers both sediment masses and water losses, is also used for the assessment of the operation's efficiency.

The results revealed that unlike the case of a horizontal bed where a venting degree of $\phi=100 \%$ led to the highest efficiency, for the two upper slopes (i.e., $2.4 \%$ and 5.0\%) the highest release efficiency was obtained with $\phi=135 \%$. This is mainly due to the fact that with higher slopes, the turbidity current reaching the outlet is less reflected upstream. The muddy lake from which the outlet extracts is thus more concentrated and for longer periods of time. Additionally, venting with higher slopes led to higher venting efficiencies for the same venting degree. Therefore, the steeper the thalweg upstream of the dam, the higher the efficiencies reached during venting.

In terms of sediment transport and river revitalization downstream of dams, the technique of venting turbidity currents, if well optimized, offers environmental benefits. It has the advantage of using relatively low outflow discharges and directly transiting the amount of fine sediments, with natural concentrations, required by the river. As no reservoir drawdown is usually needed, the water losses remain minimal. Since very fine sediments have the ability to clog small interstices needed for the fish to place their eggs, venting can be extended even after the flood to "rinse" the downstream river with clear water. Finally, transiting the fine sediments suspended by turbidity currents to the downstream environment is important, however, the coarse sediments are also crucial for a healthy ecosystem. Therefore, venting should be applied from the beginning of the dam operation and should be ideally combined with replenishment techniques which can supply coarse sediments to the downstream environment.

\section{Funding}

This work was supported by Swisselectric Research; and the Swiss Committee on Dams.

\section{Notations}

$B_{0} \quad$ Initial buoyancy flux of the turbidity current $\left(\mathrm{m}^{3} \mathrm{~s}^{-3}\right)$

$C_{\text {VENT }}$ Outflow concentration $\left(\mathrm{kgm}^{-3}\right)$

$C_{T C} \quad$ Turbidity current initial inflow concentration $\left(\mathrm{kgm}^{-3}\right)$

$d_{10} \quad$ Grain diameter for which $10 \%$ of sediments have smaller diameters $(\mathrm{m})$

$d_{50} \quad$ Mean grain size diameter $(\mathrm{m})$

$d_{90} \quad$ Grain diameter for which $90 \%$ of sediments have smaller diameters $(\mathrm{m})$

Fr Densimetric Froude number (-)

$g \quad$ Gravitational acceleration $\left(\mathrm{ms}^{-2}\right)$

$g^{\prime} \quad$ Reduced gravitational acceleration of the turbidity current at $4.1 \mathrm{~m}$ from the inlet $\left(\mathrm{ms}^{-2}\right)$

$g_{a p p}^{\prime} \quad$ Reduced gravitational acceleration of the turbidity current approaching the outlet $\left(\mathrm{ms}^{-2}\right)$ 
$g_{0}^{\prime} \quad$ Initial reduced gravitational acceleration of the turbidity current $\left(\mathrm{ms}^{-2}\right)$

$H \quad$ Average height of the current (m)

$H_{\text {head }} \quad$ Head size of the turbidity current (m)

$h_{\text {in }} \quad$ Height of the inlet $(\mathrm{m})$

$h_{L} \quad$ Critical height of aspiration of the outlet (m)

$h \quad$ Local height of the velocity profile measured by the UVP (m)

$h_{\max } \quad$ Height of the velocity profile corresponding to the maximum velocity $(\mathrm{m})$

$H_{\text {prot }} \quad$ Prototype height of turbidity current (m)

$L \quad$ Length of the main flume (m)

LVE Local Venting Efficiency (\%)

$M_{T C} \quad$ Total mass of sediments inflowing carried by the turbidity current $(\mathrm{kg})$

$M_{V E N T} \quad$ Total mass of evacuated sediments during venting ( $\mathrm{kg}$ )

$M_{\text {deptot }}$ Total mass of sediments deposited along the flume at the arrival of the current to the wall $(\mathrm{kg})$

$M_{\text {intot }} \quad$ Total mass of inflow (turbidity currents) sediments $(\mathrm{kg})$

$Q_{T C} \quad$ Turbidity current inflow discharge $\left(\mathrm{m}^{3} \mathrm{~s}^{-1}\right)$

$Q_{V E N T} \quad$ Venting outflow discharge $\left(\mathrm{m}^{3} \mathrm{~s}^{-1}\right)$

Re Reynolds number (-)

Ri Bulk Richardson number (-)

$S \quad$ Flume's bed slope (\%)

$T_{v i} \quad$ Beginning of venting (s)

$t \quad$ Duration of the test $(\mathrm{s})$

$t=\left(t-T_{v i}\right)^{2} g_{a p p}^{\prime} / h_{L}$ Normalized venting duration $(-)$

$t_{\max } \quad$ Maximum test duration (s)

$t_{\text {prot }} \quad$ Venting duration in prototype (s)

$t_{\text {sprot }} \quad$ Prototype settling time (s)

$t_{s} \quad$ Experimental settling time (s)

$u \quad$ Local velocity of the turbidity current as measured by the $\operatorname{UVP}\left(\mathrm{ms}^{-1}\right)$

$U \quad$ Average velocity of the current $\left(\mathrm{ms}^{-1}\right)$

$U_{f} \quad$ Front velocity of the turbidity current $\left(\mathrm{ms}^{-1}\right)$

$U_{\max } \quad$ Maximum velocity of the body of the turbidity current $\left(\mathrm{ms}^{-1}\right)$

$v_{s} \quad$ Sediment settling velocity $\left(\mathrm{ms}^{-1}\right)$

VEI Venting Efficiency Indicator (\%)

$x \quad$ Distance from the inlet in the experimental main flume (m)

$\alpha \quad$ Slope angle $\left(^{\circ}\right)$

$\Phi \quad$ Venting degree (\%)

$\nu \quad$ Kinematic viscosity of water $\left(\mathrm{m}^{2} \mathrm{~s}^{-1}\right)$

$\rho_{s} \quad$ Density of sediment material $\left(\mathrm{kgm}^{-3}\right)$

$\rho_{w} \quad$ Density of clear water $\left(\mathrm{kgm}^{-3}\right)$

$\rho_{t 0} \quad$ Initial density of the turbidity current $\left(\mathrm{kgm}^{-3}\right)$

\section{Appendix A. Supplementary data}

Supplementary data related to this article can be found at http:// dx.doi.org/10.1016/j.jenvman.2017.09.030.

\section{References}

Alavian, V., Jirka, G.H., Denton, R.A., Johnson, M.C., Stefan, H.G., 1992. Density currents entering lakes and reservoirs. J. Hydraul. Eng. 118 (11), 1464-1489.

Altinakar, S., Graf, W.H., Hopfinger, E.J., 1990. Weakly depositing turbidity current on a small slope. J. Hydraul. Res. 28 (1), 55-80.

Annandale, G.W., 2005. Reservoir Sedimentation. Encyclopedia of Hydrological Sciences. Wiley, Chichester, U.K.

BAUMER, 2014. UNAM 30-Ultrasonic Distance Measuring Sensors - Data Sheet.

Britter, R.E., Linden, P.F., 1980. The motion of the front of a gravity current travelling down an incline. J. Fluid Mech. 99 (3), 531-543.

Chamoun, S., De Cesare, G., Schleiss, A.J., 2016a. Managing reservoir sedimentation by venting turbidity currents: a review. Int. J. Sediment Res. 31 (3), 195-204.

Chamoun, S., De Cesare, G., Schleiss, A.J., 2016b. Venting turbidity currents for the sustainable use of reservoirs. Int. J. Hydropower Dams 23 (5), 64-69.
Chamoun, S., Zordan, J., De Cesare, G., Franca, M.J., 2016c. Measurement of the deposition of fine sediments in a channel bed. Flow Meas. Instrum. 50, 49-56.

Chamoun, S., De Cesare, G., Schleiss, A.J., 2017. Venting of turbidity currents approaching a rectangular opening on a horizontal bed. J. Hydraul. Res. http:// dx.doi.org/10.1080/00221686.2017.1289266.

Chen, J., Zhao, K., 1992. Sediment management in Nanqin reservoir. Int. J. Sediment Res. 7 (3), 71-84.

Chung, S.W., Ko, I.H., Kim, Y.K., 2008. Effect of reservoir flushing on downstream river water quality. J. Environ. Manag. 86 (1), 139-147. http://dx.doi.org/ 10.1016/j.jenvman.2006.11.031.

Craya, A., 1949. Recherches théoriques sur l'écoulement de couches superposées de fluides de densités différentes. La Houille Blanche 35 (1), 44-55.

De Rooij, F., Dalziel, S.B., 2009. Time-and space-resolved measurements of deposition under turbidity currents. In: Particulate Gravity Currents. Wiley, New York, pp. 207-215.

De Rooij, F., Dalziel, S.B., Linden, P.F., 1999. Electrical measurement of sediment layer thickness under suspension flows. Exp. Fluid 26 (5), 470-474.

Ellison, T.H., Turner, J.S., 1959. Turbulent entrainment in stratified flows. J. Fluid Mech. 6 (3), 423-448.

ENDRESS+HAUSER, 2005. Proline Promag 50W, 53W, Technical Information.

Espa, P., Brignoli, M.L., Crosa, G., Gentili, G., Quadroni, S., 2016. Controlled sediment flushing at the Cancano Reservoir (Italian Alps): management of the operation and downstream environmental impact. J. Environ. Manag. 182, 1-12. http:// dx.doi.org/10.1016/j.jenvman.2016.07.021.

Fan, J., Morris, G.L., 1992. Reservoir sedimentation I: delta and density current deposits. J. Hydraul. Eng. 18 (3), 354-369.

Fan, J., 1960. Experimental studies on density currents. Sci. Sin. 4 (2), 275-303.

Fan, J., 1986. Turbid density currents in reservoirs. Water Int. 11 (3), 107-116.

Garcia, M., Parker, G., 1993. Experiments on the entrainment of sediment into suspension by a dense bottom current. J. Geophys. Res. 98 (C3), 4793-4807.

Gariel, P., 1949. Recherches expérimentales sur l'écoulement de couches superposées de fluides de densités différentes. La Houille Blanche 35 (1), 56-64.

Graf, W.H., Altinakar, M.S., 1995. Courants de turbidité. La Houille Blanche 81 (7), $28-37$.

Kantoush, S.A., Sumi, T., 2010. River morphology and sediment management strategies for sustainable reservoir in Japan and European Alps. In: Annuals of Disaster Preventive Research Institute (pp. 821-839). Kyoto, Japan.

Kneller, B., Buckee, C., 2000. The structure and fluid mechanics of turbidity currents: a review of some recent studies and their geological implications. Sedimentology 47 (s1), 62-94.

Kneller, B., Edwards, D., McCaffrey, W., Moore, R., 1991. Oblique reflection of turbidity currents. Geology 19 (3), 250-252.

Lai, J.S., Shen, H.W., 1996. Flushing sediment through reservoirs. J. Hydraul. Res. http://dx.doi.org/10.1080/00221689609498499.

Lamb, M.P., Hickson, T., Marr, J.G., Sheets, B., Paola, C., Parker, G., 2004. Surging versus continuous turbidity currents: flow dynamics and deposits in an experimental intraslope minibasin. J. Sediment. Res. 74 (1), 148-155.

Lara, J.M., 1960. The 1957 Sedimentation Survey of Elephant Butte Reservoir. Bureau of Reclamation. U.S. Dept. of Interior, Denver.

Lee, H.-Y., Yu, W.-S., 1997. Experimental study of reservoir turbidity current. J. Hydraul. Eng. 123 (6), 520-528. http://dx.doi.org/10.1061/(ASCE)07339429(1997)123:6(520).

Lee, F.Z., Lai, J.S., Tan, Y.C., Sung, C.C., 2014. Turbid density current venting through reservoir outlets. KSCE J. Civil Eng. 18 (2), 694-705.

Lowe, D.R., 1982. Sediment gravity flows: II. Depositional models with special reference to the deposits of high-density turbidity currents. J. Sediment. Petrol. 52 (1), 0279-0297.

Meiburg, E., Kneller, B., 2010. Turbidity currents and their deposits. Annu. Rev. Fluid Mech. 42 (1), 135-156.

Metflow, S., 2014. UVP Monitor - User's Guide, Lausanne, Switzerland.

Morris, G., Fan, J., 1997. Reservoir Sedimentation Handbook: Design and Management of Dams, Reservoirs, and Watersheds for Sustainable Use. McGraw-Hill, New York.

Müller, P.J., De Cesare, G., 2009. Sedimentation problems in the reservoirs of the Kraftwerke Sarganserland - venting of turbidity currents as the essential part of the solution. General Report Q.89-R.21. In: Proc. of the 23rd Congress of the Int. Commission on Large Dams CIGB-ICOLD, vol. 2. Brasilia, Brasilia, Brazil. Q.89R.21.

Nizery, A., Braudeau, G., Bonnin, J., 1952. La station du Sautet pour l'étude de l'alluvionnement des réservoirs. In: Proc. Transport hydraulique et décantation des matériaux solides, pp. 180-218. France.

Oehy, C. 2003. Effects of obstacles and jets on reservoir sedimentation due to turbidity currents. In: Schleiss, A. (Ed.), PhD Thesis No. 2684, Communication 15, Laboratory of Hydraulic Constructions (LCH). Ecole Polytechnique Fédérale de Lausanne EPFL, Switzerland.

Palmieri, A., Shah, F. Dinar, A., 2001. Economics of reservoir sedimentation and sustainable management of dams. J. Environ. Manag. 61 (2), 149-163.

Raud, J., 1958. Les soutirages de vases au barrage d'Iril Emda (Algérie). In: 6th ICOLD, Com. 31, New York.

Schleiss, A., De Cesare, G., Althaus, J.J., 2010. Verlandung der Stauseen gefährdet die nachhaltige Nutzung der Wasserkraft. Wasser, Energie, Luft - Eau, Energie, Air 102 (1), 31-40.

Schleiss, A.J., Franca, M.J., Juez, C., De Cesare, G., 2016. Reservoir sedimentation. Vision paper. J. Hydraul. Res. 54 (6), 595-614.

Schleiss, A.J., 2013. Sedimentation of reservoirs. In: Encyclopedia of Natural 
Hazards. Springer Netherlands, pp. 901-905.

Schneider, J., Badura, H., Troy, W. Knoblauch, H., 2007. Determination of parameters for venting turbidity currents. In: IAHR Congress Vol. 32, No. 1 (p. 425). Venice, Italy.

Simpson, J.E., Britter, R.E., 1979. The dynamics of the head of a gravity current advancing over a horizontal surface. J. Fluid Mech. 94 (3), 477-495.

Sinniger, R.O., De Cesare, G., Martini, O., 1994. Apports de sédiments dans une retenue par courant de fond, mesures in situ. In: XVIII ICOLD Congress Q.69, R.7 (pp. 85-98). Durban.

Xu, J.P., Noble, M.A., Rosenfeld, L.K., 2004. In-situ measurements of velocity strucure within turbidity currents. Geophys. Res. Lett. 31 (9).

Yu, W.-S., Hsu, S.M., Fan, K.-L., 2004. Experiments on selective withdrawal of a codirectional two-layer flow through a line sink. J. Hydraul. Eng. 130 (12) 1156-1166. 